\title{
Improving the process efficiency of atomic layer deposition of alumina for its sustainability improvement: a combined experimental and modeling study
}

\author{
Yuanyuan Xie, Dongqing Pan, Lulu Ma, Chris Yuan* \\ Department of Mechanical Engineering, University of Wisconsin Milwaukee, WI 53211, USA \\ *Corresponding author. Tel: +1 414229 5639; Fax: +1 414229 6958; E-mail: cyuan@uwm.edu
}

\begin{abstract}
Atomic Layer Deposition (ALD) technology has been under rapid development toward a broad array of applications, while the low deposition efficiency and heavy waste of TMA are limiting its industrial-scale applications. In this paper, a mathematical model is developed based on an experimental ALD of alumina process, and an optimization approach is then proposed to investigate the optimal ALD operating for the minimum TMA wastes and the maximum $\mathrm{Al}_{2} \mathrm{O}_{3}$ production under various conditions. Results show that the maximum TMA adsorption and alumina production cannot be achieved simultaneously, but sufficient $\mathrm{H}_{2} \mathrm{O}$ dosing can minimize the gap between them. The influence of substrate surface saturation condition and operating temperature is also investigated. Results quantitatively show that lower surface saturation condition requires more ALD cycles to improve the precursors' utilization efficiency, while the optimal ALD process can increase the maximum alumina production from $2.7 \times 10^{-4} \mathrm{~mol} / \mathrm{m}^{2}$ to $7.5 \times 10^{-4} \mathrm{~mol} / \mathrm{m}^{2}$ with the temperature rise from $150^{\circ} \mathrm{C}$ to $200^{\circ} \mathrm{C}$. Besides, it is found that the maximum production of both $\mid-\mathrm{Al}\left(\mathrm{CH}_{3}\right)_{2}$ and alumina is influenced by their corresponding half-cycle duration, and sufficient treatment time can significantly improve the ALD process efficiency and reduce the total TMA waste. These insights into the minimum TMA waste and maximum production of surface products can guide the future design of ALD of alumina process with better efficiency and sustainability.
\end{abstract}

Keywords: Atomic layer deposition; Optimization; Alumina film; Process efficiency

\section{Introduction}


Atomic layer deposition (ALD) has been widely recognized as one of the promising deposition technologies in manufacturing conformal inorganic material layers [1]. It has the capability to deposit highly uniform and conformal thin films on extremely complex shape surfaces [2]. Based on the needs of specific applications, a great variety of ALD processes has been developed in the past years, while the typical process is usually studied on the deposition of $\mathrm{Al}_{2} \mathrm{O}_{3}$ barrier layer using trimethylaluminum (TMA) and water vapor as the metal-source and oxygen-source precursor respectively [3]. In this ALD process, the substrate is placed in a sealed reactor chamber and exposed to precursors in alternating pulses, where purging process is performed between pulses to effectively avoid reactions between precursors in gas phase. Due to the self-limiting characteristic of gas-surface reactions, the generated $\mathrm{Al}_{2} \mathrm{O}_{3}$ film thickness only depends on the number of ALD reaction cycles, and hence it provides extremely high uniformity and precise thickness control down to nanometer scale [4].

The use of such kind ALD of alumina process has been demonstrated in a broad array of applications from the catalysts to semiconductor chips, optical filters and beyond [5,6], and research works have been carried out on various specific aspects: the surface functionalization of nano-structures [7,8], growth of alumina film on complex polymer substrate [9] and metal surface [10], thermosmechanical properties and stress behaviors of alumina film [11,12], electrical properties of $\mathrm{ALD} \mathrm{Al}_{2} \mathrm{O}_{3}$ film when it is used as protective coating for micro-electromechanical systems [13], and the sustainability, energy and exergy analysis of the ALD of alumina process [3,14]. Although the quality of deposited alumina film has been greatly improved in current industrial manufacturing, the heavy waste of precursor gas, TMA, and its related low deposition efficiency is still a critical issue limiting its development $[3,15]$. Because TMA is a flammable chemical, it can actively react with hydroxyls and the water molecules in air. The oversupplied TMA can be converted into nano-particles and other gas waste in the emission of actual ALD process [15]. Therefore, in order to improve the sustainability performance of ALD technology, it requires increasing the efficiency of both the TMA utilization and the alumina deposition in future industrial-scale manufacturing process. 
In comparison with the experimental investigations, physical based modeling of ALD process provides significant advantages to explore the fundamental ALD reaction kinetics and the deposited film growth. Because the ALD-grown film is on atomic scale and significantly depends on the heterogeneous surface chemical processes, the surface chemical kinetics is crucial for ALD process dynamics [16]. In this respect, first principle method has been proved as an effective way to study the structure, energetics and other properties on the material's surface: Delabie et al. [17] calculated the $\mathrm{TMA}+\mathrm{H}_{2} \mathrm{O}$ reaction on hydroxyl and thiol terminated semiconductor substrates, where they theoretically analyzed the possible mechanisms for the growth inhibition by the ALD cycles. Elliott et al. [18] used the density functional theory to simulate the ALD process of alumina film formation. They investigated the atomic-scale structure of the hydroxylated alumina surfaces and the reactivity of the reaction intermediates. Similar works can also be found from Shirazi et al. [19], Huang et al. [20] and Warburton et al. [21], which all focused on the modeling of nano-scale ALD process and substrate surface transitions. Based on these fundamental works, the surface chemistry models can be successfully developed. Deminsky et al. [22] proposed a reaction kinetics model of zirconium and hafnium oxide film growth within the ALD reactor. Travis et al. $[23,24]$ developed a surface film growth model to investigate the ALD film growth as a function of various process parameters. Although these proposed surface chemical kinetics works can successfully explain the film growth dynamics, the effect of the complicated precursor injection and transport processes were neglected. To overcome this shortcoming, Holmqvist et al. [4, 25-27] presented a series of works on the $\mathrm{Zn}\left(\mathrm{C}_{2} \mathrm{H}_{5}\right)_{2}$ - $\mathrm{ZnO}$ ALD process, where the detailed gas-surface reactions were coupled with the continuum gas flow in their multi-physics modeling development. Xie et al. [28] studied ALD of alumina process, and proposed a detailed mathematical model, where the surface reaction kinetics of alumina formation was incorporated into the precursor injecting and purging process. Through these modeling, it is recognized that very strong interdependency exists among precursor injection, gas transport, surface reaction, and alumina film growth. The change on one operating parameter does not necessarily lead to the improvement of alumina film generation; on the contrary, it may cause negative 
effect. For example, large dose injection of precursors can intensify the surface reactions of alumina deposition, but meanwhile, will lead to low utilization efficiency of precursors. Therefore, the competing nature of those properties requires an optimized design on ALD of alumina process. Especially, the alumina film growth is nonlinearly dependent on multi operating parameters associated with the ALD manufacturing process.

In this study, a mathematical model is developed based on an experimental ALD of alumina process, and an optimization approach is developed to study the ALD system process efficiency on alumina deposition and emissions. The ALD process model is firstly established to bridge surface chemical reactions on the substrate surface with the fluid dynamics in the ALD reactor chamber, while a corresponding ALD of alumina experiment is carried out to validate the modeling results. Then, optimization calculation is conducted to find optimal ALD operation parameters under different operating conditions for maximum TMA utilization and alumina deposition.

\section{Experiment details}

The experimental ALD of alumina process is conducted in Cambridge NanoTech Savannah S100 system using TMA and water vapor as precursors (Figure 1), where a silicon wafer (substrate) with radius of $50 \mathrm{~mm}$ is placed in the center of S100 reactor chamber, and flushed over with nitrogen (inert gas) in the beginning. When the chamber is heated to the deposition temperature, the first treatment begins with injecting a sufficient water vapor pulse into the reactor to fully hydroxylate the silicon wafer surface. After that, the reactor chamber is purged by the inert gas for a few seconds and followed by the gas-phase TMA pulse, which will be chemisorbed and react with the hydroxyl groups on the substrate surface. Then, the reactor chamber is purged with the inert gas once again, and treated by the second water vapor pulse. After the chemisorption of the water vapor onto the substrate surface, the reaction will take place between the adsorbed vapor molecule and the surface species, and an alumina dielectric film can be produced on 
the silicon wafer surface. The global reactions of these two precursor pulse treatment (two half-cycles) are given by,

$$
\begin{aligned}
& \text { TMA half-cycle: } \quad \mathrm{O}_{\perp(s)}+\mathrm{Al}\left(\mathrm{CH}_{3}\right)_{3(g)} \stackrel{k_{1}}{\Rightarrow} \underset{\perp}{\mathrm{O}}-\mathrm{Al}\left(\mathrm{CH}_{3}\right)_{2(s)}+\mathrm{CH}_{4(g)} \\
& \mathrm{H}_{2} \mathrm{O} \text { half-cycle: } \quad \underset{\perp}{\mathrm{O}}-\mathrm{Al}\left(\mathrm{CH}_{3}\right)_{2(s)}+2 \mathrm{H}_{2} \mathrm{O}_{(\mathrm{g})} \stackrel{\mathrm{k}_{2}}{\Rightarrow} \underset{\perp}{\mathrm{O}}-\mathrm{Al}-2 \mathrm{OH}_{(s)}+2 \mathrm{CH}_{4(g)}
\end{aligned}
$$

where, $\perp$ (or $\mid-)$ stands for the substrate surface; $(s)$ denotes the surface species; $(g)$ is the gas phase; $k_{1}$ and $k_{2}$ are the surface reaction rates respectively. Because the silicon wafer surface can be hydroxylated again after the $\mathrm{H}_{2} \mathrm{O}$ pulse, with the next round of $\mathrm{TMA}+\mathrm{H}_{2} \mathrm{O}$ reaction, the alumina film can be continuously deposited on the target silicon wafer surface.

In this work, the pressure of reactor chamber is tuned by altering the balance status between the gas flow rate at inlet and the pumping rate at outlet, and is maintained at around 1 Torr. The injection durations of the applied TMA pulse $\left(\mathrm{P}_{\mathrm{TMA}}\right)$ and $\mathrm{H}_{2} \mathrm{O}$ pulse $\left(\mathrm{P}_{\mathrm{H} 2 \mathrm{O}}\right)$ are set at $0.015 \mathrm{~s}$ and $0.03 \mathrm{~s}$ respectively, and their partial pressures are both 0.15 Torr. Nitrogen is used as the purging gas, and the purging time between two precursor pulses is set at $8 \sim 10$ seconds. On the silicon wafer surface, we selected five different sites to measure the deposited film thickness using a spectroscopic ellipsometer (Horidba UVISEL model), and four chamber temperature conditions: $100^{\circ} \mathrm{C}, 150^{\circ} \mathrm{C}, 200^{\circ} \mathrm{C}$ and $250^{\circ} \mathrm{C}$, are applied to the process respectively. As shown in figure 1, the deposited alumina film thickness in all five sites is around $61 \AA$ after 60 ALD cycles at $100^{\circ} \mathrm{C}$. Although the film thickness varies by around $4 \AA$ with $50^{\circ} \mathrm{C}$ increase on the operation temperature, the difference of measured film thickness among five surface sites is less than $5 \AA$ ( $8 \%$ of the total film thickness). These observations indicate that the deposited alumina film has very high uniformity in the reactor with above operation conditions. Besides, at the outlet of S100 system, the process emissions are also analyzed: the concentration of emitted species (e.g. $\left.\mathrm{CH}_{4}\right)$ is measured by ultrafine condensation particle counter (UCPC, TSI 3776). Meanwhile, a scanning mobility 
particle sizer (SMPS, TSI 3936) is used to obtain the emitted particle size and distribution, which consists of an electrostatic classifier (TSI 3080) and UCPC [29]. Based on this experiment, the process efficiency and alumina film production will be analyzed, and the obtained alumina film thickness and process emission will also be used to validate the mathematical model developed in the following sections.

\section{ALD of alumina process modeling}

Because the ALD of alumina is in a repeated cycle manner, and the precursors, TMA and water vapor, are injected individually in an alternating sequence, several key assumptions can be applied in the model development:

- According to R.Puurunen [16], the alumina film deposited during one $\mathrm{TMA}+\mathrm{H}_{2} \mathrm{O}$ cycle on substrate surface can be assumed to be a monolayer;

- Heat production and consumption of surface reactions are negligible during ALD process, so that an isothermal condition can be assumed during cycling operations $[3,15,28]$;

- The alumina film formation during each ALD cycle is assumed to be independent;

- The adsorption reactions of gas phase TMA and $\mathrm{H}_{2} \mathrm{O}$ are assumed to be the rate-limiting steps;

- According to Travis et al. [23,24], the maximum density of $\mid-\mathrm{OH}$ and $\mathrm{Al}_{1} \mathrm{O}_{3 / 2}$ on the substrate surface are assumed as $17.2 \mathrm{~nm}^{-2}$ and $11.5 \mathrm{~nm}^{-2}$ respectively in one ALD cycle.

To keep the conciseness and compactness of the paper, the governing equations of TMA/ $\mathrm{H}_{2} \mathrm{O}$ surface reactions and flow in ALD reactor are summarized in Table 1, which include the surface adsorption reaction rates of precursors, the Navier-Stokes equations for the compressible cross-flow in the ALD chamber, and the mass conservation equation. The mass fluxes induced by surface chemical process of precursors are coherently coupled into the momentum and mass conservation equations. Similar to our previous study [28], a 2-dimensional geometry is applied to model the cross-flow in S100 reactor chamber, where inlet/outlet tube boundaries are applied instead of complicated precursor gas tanks and vacuum pump for the convenience of modeling. The operating conditions and initial boundaries of the 
model is the same as our experiment: the operating temperature in the reactor is maintained at a constant value, as well as the walls of inlet/outlet tube and reactor chamber. Because the actual process pressure in the experiment (around 1 Torr) is tuned by altering the balance status between the gas flow rate at the inlet and the pumping rate at outlet, the chamber inlet and outlet pressures of $\mathrm{N}_{2}$ flow are set as 1Torr and 0.9Torr (as read values in S100) respectively. A time dependent pulse pressure, 1 Torr $+\mathrm{P}_{\mathrm{TMA}} / \mathrm{P}_{\mathrm{H} 2 \mathrm{O}}$, is applied at the inlet boundary, where $\mathrm{P}_{\mathrm{TMA}}$ is around 0.015Torr and $\mathrm{P}_{\mathrm{H} 2 \mathrm{O}}$ is 0.03Torr. Table 2 has summarized the associated modeling parameters and boundaries. The commercial software package COMSOL Multiphysics is used to solve the coupled governing equations. Figure 2 illustrates the comparison between the numerical results and the experimental data, which includes the deposited film thickness on silicon wafer surface and the collected $\mathrm{CH}_{4}$ production. It can be seen that our modeling results match with the experimental data reasonably well expect that the numerical results are slightly larger on the thickness prediction and a little smaller on $\mathrm{CH}_{4}$ production. This can be explained by that the modeling has assumed the surface reactions between precursors and chamber walls were negligible, which can overestimate the precursor concentration on the top of the substrate surface during cycles, and eventually leads to the overestimation of the deposited alumina film thickness as well as the underestimation of $\mathrm{CH}_{4}$ production. Based on this ALD process model, an optimization approach will be carried out to investigate the optimal $\mathrm{ALD} \mathrm{Al}_{2} \mathrm{O}_{3}$ process.

\section{Model based optimization approach}

\subsection{Adjustable variables and constraints}

Basically, sustainable development of ALD technology requires improving the deposition efficiency of alumina and reducing the toxic emissions from the ALD process [3,15,29]. For this objective, in our optimization study, the total ALD operation time $\left(t_{N}^{\text {tot }}\right)$ and the total amount of TMA $\left(C_{T M A}^{\text {tot }}\right)$ and $\mathrm{H}_{2} \mathrm{O}\left(C_{\mathrm{H}_{2} \mathrm{O}}^{\text {tot }}\right)$ are set as given parameters, while the adjustable variables are the precursor doses per cycle 
$\left(C_{T M A}^{p c}, C_{H_{2} O}^{p c}\right)$, the half-cycle time $\left(\Delta t, \Delta t=\Delta t_{T M A}=\Delta t_{H_{2} O}=\Delta t_{\text {pulse }}+\Delta t_{\text {purge }}\right)$ and the total ALD cycle number $(N)$. They can be summarized in a general form $\mathrm{x}$ :

$$
x=\left[C_{T M A}^{p c}, C_{H_{2} O}^{p c}, \Delta t, N\right]
$$

Since the ALD of alumina operates by repeated cycles, our optimization will be conducted in one ALD cycle and assumes that all ALD cycles have the same surface species' production. Then, the adjustable parameters can be subject to following constraint region $R$ :

$$
R=\left\{\begin{array}{l}
1 \leq N, 1 \leq \Delta t_{T M A}, 1 \leq \Delta t_{H_{2} \mathrm{O}} \\
0<C_{T M A}^{p c} \leq C_{T M A}^{t o t}, 0<C_{\mathrm{H}_{2} \mathrm{O}}^{p c} \leq C_{H_{2} \mathrm{O}}^{t o t} \\
C_{T M A}^{p c} \times N=C_{T M A}^{t o t}, C_{\mathrm{H}_{2} \mathrm{O}}^{p c} \times N=C_{\mathrm{H}_{2} \mathrm{O}}^{t o t} \\
\left(\Delta t_{T M A}+\Delta t_{\mathrm{H}_{2} \mathrm{O}}\right) \times N=t_{N}^{t o t}
\end{array}\right.
$$

where, the half-cycle time $\Delta t_{T M A}$ and $\Delta t_{\mathrm{H}_{2} \mathrm{O}}$ are both larger than 1 second. This definition is to avoid the possible reactions between two precursors in gas phase induced by too short purging time [30].

\subsection{Objective functions}

In principle, the toxic emissions of the ALD of alumina operation are mainly from the oversupplied TMA precursor. Hence, the objective functions of our optimization are set as the minimization of TMA waste and the maximization of alumina deposition. Based on the chemical kinetics of TMA and $\mathrm{H}_{2} \mathrm{O}$ on the substrate surface, the gas-surface reactions during ALD operation are nearly irreversible by the removal of methane. Therefore, the amount of reacted TMA is analogous to its surface product concentration $\left(\mathrm{C}_{\mid-\mathrm{Al}_{2}\left(\mathrm{CH}_{3}\right)_{2}}^{\text {prd }}\right)$ in TMA half-cycle, while the deposited alumina film in each ALD cycle $\left(l_{A l_{1} O_{3 / 2}}^{g p c}(x)\right)$ can be determined by the produced alumina $\left(C_{A l_{1} O_{3 / 2}}^{p r d}\right)$ in $\mathrm{H}_{2} \mathrm{O}$ half-cycle. The objective functions then can be formulated as,

1) Minimize TMA waste 


$$
\min _{x \in R}\left(C_{T M A}^{t o t}-N \times C_{T M A}^{r e c}\right)=\max _{x \in R}\left(N \times C_{\mid-A_{2}\left(\mathrm{CH}_{3}\right)_{2}}^{\text {prd }}\right)
$$

2) Maximize alumina production

$$
\max _{x \in R}\left(N \times l_{A l_{1} O_{3 / 2}}^{g p c}(x)\right)=\max _{x \in R}\left(N \times C_{A l_{1} O_{3 / 2}}^{p r d}\right)
$$

\subsection{Solution algorithm and environment}

The optimization procedure of ALD of alumina is conducted by MATLAB in combination with the developed multi-physical ALD model in COMSOL Multiphysics: the ALD model is firstly decoded in the MATLAB, then in the constraint region R, the MATLAB functions 'fmincon' and 'fminimax' are used in our in-house program to find the optimal process based on the objective functions. To determine the optimal value for maximum TMA deposition and maximum alumina, we choose the intersection point between the curve of TMA deposition and the curve of alumina production as the optimal value. Because the amount of TMA surface deposition product is surely more than that of the deposited alumina, this point of intersection can be located before the maximum TMA deposition but after the maximum alumina production. Figure 2 schematically illustrates the flowchart of this optimization procedure, which begins with the initial population of parameter $\mathrm{x}$ in constraint region $\mathrm{R}$. By parallel processing, the ALD operation process is simulated and the objective functions are calculated. If the convergence criterion is not met, the intermediate selections and population of $\mathrm{x}$ are generated, and the ALD model is updated by using new $\mathrm{x}$ and the objective functions are calculated again till all stop conditions are satisfied. In this study, our stop conditions consist of the convergence of multi-physics model calculation (errors $<10^{-6}$ ), and the gradients of TMA deposition $\left(\mathrm{G}_{\mathrm{TMA}}\right)$ and alumina production $\left(\mathrm{G}_{\mathrm{Al}}\right)$ till the intersection point is found in the region of $\mathrm{G}_{\mathrm{TMA}}>0$ and $\mathrm{G}_{\mathrm{Al}}<0$. Here, we would like to emphasize that it is assumed that the ALD cycles are self-independent, hence, minimizing TMA waste only depends on the TMA dose and

cycle number, while the calculation of maximizing the alumina film production considers both TMA halfcycle and $\mathrm{H}_{2} \mathrm{O}$ half-cycle operations. Besides, in order to figure out the relationship between TMA half- 
cycle and $\mathrm{H}_{2} \mathrm{O}$ half-cycle, parameter studies are also carried out to find the effect of different $\mathrm{x}$ on the amount of adsorbed TMA and deposited alumina. The associated parameters of ALD process modeling are summarized in Table 2, while the parameter definitions are listed in the nomenclature.

\section{Results and discussion}

\subsection{Optimal ALD operation and precursor dose effect}

The dose ratio between precursor TMA and precursor $\mathrm{H}_{2} \mathrm{O}$ has significant influence on the alumina film production. According to the research works conducted by O.Ylivaara et al. [31] and M.Ghosh et al. [32], sufficient $\mathrm{H}_{2} \mathrm{O}$ dose can effectively improve the uniformity and production of alumina film on the substrate surface. To investigate this effect on the ALD of alumina process, we carry out eight individual experiments by controlling the applied precursor dose in Savannah S100 system. As shown in figure 4 , four pulse time settings (TMA- $\mathrm{H}_{2} \mathrm{O}$ ): $0.015 \mathrm{~s}-0.015 \mathrm{~s}, 0.03 \mathrm{~s}-0.015 \mathrm{~s}, 0.015 \mathrm{~s}-0.03 \mathrm{~s}$ and $0.03 \mathrm{~s}-0.03 \mathrm{~s}$, are applied respectively, while the process purging time is set at $8 \mathrm{~s}$ and $20 \mathrm{~s}$. It can be seen that after 60 cycles, the average GPC of alumina film is nearly the same between $0.015 \mathrm{~s}-0.015 \mathrm{~s}$ case and $0.03 \mathrm{~s}-0.015 \mathrm{~s}$ case under the purging time at $8 \mathrm{~s}$ condition, but when the $\mathrm{H}_{2} \mathrm{O}$ dose is increased to $0.03 \mathrm{~s}$, the GPC can be increased by nearly $10 \%$. These phenomena prove that more $\mathrm{H}_{2} \mathrm{O}$ dose can effectively improve the TMA adsorption and increase the alumina film production. Meanwhile, when the purging time is increased to $20 \mathrm{~s}$, it can be seen that the $0.015 \mathrm{~s}-0.015 \mathrm{~s}$ case has the lowest GPC due to its smaller TMA does, but the GPC of $0.015 \mathrm{~s}-0.03 \mathrm{~s}$ case can reach nearly the same as that of the $0.03 \mathrm{~s}-0.015 \mathrm{~s}$ case and $0.03 \mathrm{~s}-0.03 \mathrm{~s}$ case even it has the same small TMA dose. These observations indicate that the ALD process efficiency is not only determined by the supplied precursors' dose, but also affected by the transport and chemical process taking place in the chamber.

To investigate the ALD of alumina efficiency behind these experimental observations, the optimal ALD process for the maximum TMA utilization efficiency is investigated by our developed modeling approach. Figure 5 illustrates the optimal ALD cycle numbers along with different total amount 
of TMA under three TMA/ $\mathrm{H}_{2} \mathrm{O}$ dose-ratio conditions, 1:1, 1:2 and 1:3, respectively. The operation temperature is set at $200^{\circ} \mathrm{C}$, and the total ALD treatment time is 200 seconds. It can be seen that, under certain amount of TMA, the optimal ALD cycle number for maximum alumina film production and minimum TMA waste increases with the rise of $\mathrm{H}_{2} \mathrm{O}$ dose. Because the produced alumina film is a monolayer and is limited in one ALD treatment cycle, the generated film thickness is undoubtedly the largest in 1:3 case comparing with the other two. With the increase of TMA amount, it can also be noted from figure 5 that the gap on the optimal ALD cycles among three cases is continuously increasing. This observation indicates that the TMA utilization efficiency becomes increasingly worse under small $\mathrm{H}_{2} \mathrm{O}$ dose condition if the TMA amount is increased. To further investigate the relationship between TMA half-cycle and $\mathrm{H}_{2} \mathrm{O}$ half-cycle, figure 6 presents two parameter studies on the production of surface species|- $\mathrm{Al}\left(\mathrm{CH}_{3}\right)_{2}$ and alumina along with ALD cycles (or precursor dose since $C_{T M A / H 2 O}^{p c} \times N=C_{T M A / H 2 O}^{t o t}$ ). The total TMA amount is set at $0.1 \mathrm{~mol}$, while the operating temperature is $200^{\circ} \mathrm{C}$. In figure $6 \mathrm{a}$, we assumed the silicon wafer surface can be ideally hydroxyled in each $\mathrm{H}_{2} \mathrm{O}$ half-cycle treatment, so that the adsorption of TMA molecule can be maximized in each TMA half-cycle. It can be seen that the production of $\mid-\mathrm{Al}\left(\mathrm{CH}_{3}\right)_{2}$ on the substrate surface can reach a peak value to nearly $9 \times 10^{-4} \mathrm{~mol} / \mathrm{m}^{2}$ when the ALD cycle number is around 34. Since the TMA amount is constant and the surface sites for TMA chemisorption are limited on silicon wafer, this peak indicates the utilization efficiency of TMA is maximized. By taking the $\mathrm{H}_{2} \mathrm{O}$ dose effect into consideration, figure $6 \mathrm{~b}$ presents the effect of molar ratios between TMA dose and $\mathrm{H}_{2} \mathrm{O}$ dose on the alumina film production. It shows that increasing the $\mathrm{H}_{2} \mathrm{O}$ dose from 1:1 to $1: 2$ and 1:3 can efficiently improve the alumina film production. This is not surprising since more $\mathrm{H}_{2} \mathrm{O}$ supply can increase the local $\mathrm{H}_{2} \mathrm{O}$ concentration on the top of substrate surface and intensify the chemical reactions with surface $\mid-\mathrm{Al}\left(\mathrm{CH}_{3}\right)_{2}$ groups. Besides, it also shows that the cycle numbers for maximum $\mid-\mathrm{Al}\left(\mathrm{CH}_{3}\right)_{2}$ production and maximum alumina production are different, but increasing the $\mathrm{H}_{2} \mathrm{O}$ dose can move the ALD cycle number needed for the maximum alumina production towards the ALD cycle number needed for the maximum $\mid-\mathrm{Al}\left(\mathrm{CH}_{3}\right)_{2}$ production. These observations suggest that at a fixed 
ALD treatment time, due to the different surface reaction rate and conversion efficiency in two halfcycles, the practical ALD operating is difficult to achieve maximum TMA adsorption and maximum alumina production simultaneously but can only minimize the gap between them through providing sufficient $\mathrm{H}_{2} \mathrm{O}$ dose.

\subsection{Comparison of different saturation conditions on substrate surface}

In principle, the available surface sites of substrate for TMA adsorption and alumina film formation cannot be fully occupied. This is not only because of the limited cycling treatment time, but also due to the fact that surface adsorption and desorption reactions are taking place simultaneously. According to the Arrhenius theory, it is recognized that the increase of surface product concentration can intensify the backward desorption reactions, and eventually lead to an equilibrium state between supplied precursors and surface adsorbed products. Hence, the saturation state on our silicon wafer surface is that the surface coverage of produced either $\mid-\mathrm{Al}\left(\mathrm{CH}_{3}\right)_{2}$ or $\mathrm{Al}_{1} \mathrm{O}_{3 / 2}$ is less than $100 \%$. Because it is quite difficult to experimentally study different surface saturation conditions, in this section, we will assume three equilibrium state conditions and numerically investigate the optimal ALD process for their process efficiency. As shown in figure 7, the maximum surface sites that can be occupied on substrate surface are defined according to the maximum surface densities of $\mid-\mathrm{OH}$ and $\mathrm{Al}_{1} \mathrm{O}_{3 / 2}$, while three saturation conditions, $100 \% \mathrm{C}_{\mathrm{av}}$ (fully covered), $80 \% \mathrm{C}_{\mathrm{av}}$ and $50 \% \mathrm{C}_{\mathrm{av}}$, are applied respectively. The molar ratio between TMA and $\mathrm{H}_{2} \mathrm{O}$ is set at 1:2, while the other parameters are the same as above cases and experiment. It can be seen that optimal cycles for minimum TMA waste and maximum alumina production are quite different among three cases: $50 \% \mathrm{C}_{\mathrm{av}}$ case obviously requires more $\mathrm{ALD}$ cycles than the other two cases to improve the precursors' utilization efficiency, while the difference of their optimized cycle number increases with the applied total amount of TMA. Parameter studies are also carried out to investigate this effect on the amount of $\mid-\mathrm{Al}\left(\mathrm{CH}_{3}\right)_{2}$ and $\mathrm{Al}_{1} \mathrm{O}_{3 / 2}$ production. It can be seen from figure $8 \mathrm{a}$ that the ALD cycle number for maximum $\mid-\mathrm{Al}\left(\mathrm{CH}_{3}\right)_{2}$ production increases when the available surface sites decrease from $100 \% \mathrm{C}_{\mathrm{av}}$ to $50 \% \mathrm{C}_{\mathrm{av}}$. This is reasonable since that less TMA 
adsorption rate per cycle can result in a smaller precursor dose to reduce the total TMA waste. Besides, it can also be seen that the maximum $\mid-\mathrm{Al}\left(\mathrm{CH}_{3}\right)_{2}$ production can be significantly reduced if the surface sites are decreased from $100 \% \mathrm{C}_{\mathrm{av}}$ to $50 \% \mathrm{C}_{\mathrm{av}}$. This can be understood by that the global deposition efficiency of ALD process has been reduced by a limited surface sites condition. The effect of substrate surface condition on the alumina production is shown in figure $8 \mathrm{~b}$, where the alumina film production has the same reduction trends as the $\mid-\mathrm{Al}\left(\mathrm{CH}_{3}\right)_{2}$ species when the surface sites decreases. This is because the produced $\mid-\mathrm{Al}\left(\mathrm{CH}_{3}\right)_{2}$ species in TMA half-cycle determines the amount of alumina film production.

\subsection{Effect of ALD operating temperature}

The operating temperature can significantly influence the surface reaction rate of precursors and the coupled cross-flow in the reactor during the ALD of alumina process. Considering the surface desorption reactions can be greatly intensified when the operating temperature is over $200^{\circ} \mathrm{C}[18]$, the numerical $\mathrm{ALD} \mathrm{Al} \mathrm{O}_{3}$ process is operated under $150^{\circ} \mathrm{C}, 180^{\circ} \mathrm{C}$ and $200^{\circ} \mathrm{C}$ respectively. Their effect on the optimal ALD process is illustrated in Figure 9. The applied dose ratio between TMA and $\mathrm{H}_{2} \mathrm{O}$ is set at 1:2, while the total amount of TMA is $0.1 \mathrm{~mol}$. It can be seen that the optimal ALD cycle number of all three cases increases with the increase of total ALD operating time, but clearly, the optimal cycles under $200^{\circ} \mathrm{C}$ condition is much larger than that of $150^{\circ} \mathrm{C}$ and $180^{\circ} \mathrm{C}$, where this difference continuously increases with the total treatment time. This observation suggests that although low operating temperature can result in a limited production of surface species, sufficient ALD operation time can make up for it and increase the total TMA utilization efficiency. The effect of operating temperatures on the $1-\mathrm{Al}\left(\mathrm{CH}_{3}\right)_{2}$ and $\mathrm{Al}_{1} \mathrm{O}_{3 / 2}$ production is also studied and illustrated in figure 10. It can be seen that the maximum $\mid-\mathrm{Al}\left(\mathrm{CH}_{3}\right)_{2}$ production increases from $3 \times 10^{-4} \mathrm{~mol} / \mathrm{m}^{2}$ to $9 \times 10^{-4} \mathrm{~mol} / \mathrm{m}^{2}$ with the temperature rise from $150^{\circ} \mathrm{C}$ to $200^{\circ} \mathrm{C}$, while its corresponding ALD cycle number is increased as well. This can be understood by the fact that the temperature rise has intensified the chemisorption rate of TMA, so that a smaller dose TMA per cycle has increased the total $1-\mathrm{Al}\left(\mathrm{CH}_{3}\right)_{2}$ production. Similarly, in the $\mathrm{H}_{2} \mathrm{O}$ half-cycle, figure $10 \mathrm{~b}$ 
illustrates the effect of operating temperature on the alumina production under different designed ALD cycles. It also shows that the maximum alumina production can increase from $2.7 \times 10^{-4} \mathrm{~mol} / \mathrm{m}^{2}$ to $7.5 \times 10^{-4} \mathrm{~mol} / \mathrm{m}^{2}$ with the temperature rise from $150^{\circ} \mathrm{C}$ to $200^{\circ} \mathrm{C}$, and the corresponding ALD cycle number increases with the temperature rise as well. These observations suggest that the optimal ALD process for minimum TMA waste and maximum alumina film production varies significantly with ALD operating temperature.

The effect of operating temperature on the optimal ALD process is also investigated by the experiment, where we collected the process emissions including the produced $\mathrm{CH}_{4}$ and nano-particles under different operating temperatures, and five purging time conditions, 2s, $8 \mathrm{~s}, 12 \mathrm{~s}, 16 \mathrm{~s}$ and $20 \mathrm{~s}$, are applied respectively. After 25 cycles, it can be seen from figure 11 that increasing the purging time of ALD process from $2 \mathrm{~s}$ to $8 \mathrm{~s}$ can slightly reduce the amount of average $\mathrm{CH}_{4}$ production of one ALD cycle in the process emission from about $6 \%$ to $4 \%$, but when the purging time is further increased from $8 \mathrm{~s}$ to 20s, the molar fraction of $\mathrm{CH}_{4}$ nearly stays unchanged at around $4 \%$. Similarly, the variation of nanoparticle number in the process emission is also shown in figure 11, where the average nanoparticle number of one cycle is decreased from about $2 \times 10^{6}$ to $1 \times 10^{6}$ when the purging time increases from $2 \mathrm{~s}$ to $12 \mathrm{~s}$, but it nearly remains constant at around $1 \times 10^{6}$ when the purging time further increases from $12 \mathrm{~s}$ to 20s. This can be understood by that a longer purging time can provide more reaction time for surface adsorption of precursors. Besides, it can also be seen that the effect of operating temperature on the nanoparticle number varies with the purging time. Since the oversupplied TMA is the only source for the production of those nanoparticles and the total applied TMA is the same, these phenomena prove that the purging time designed for maximum TMA utilization efficiency should vary with the operating temperatures during ALD manufacturing process.

\subsection{Effect of ALD half-cycle durations}


In general, the half-cycle treatment of ALD operation is typically composed of two processes: the precursor pulse period and the purging period. The surface chemical reactions between precursors and substrate surface typically can take place in both pulse period and early purging period [28]. Because of the different adsorption reaction rates of TMA and $\mathrm{H}_{2} \mathrm{O}$, the equal half-cycle treatment time of TMA pulse and $\mathrm{H}_{2} \mathrm{O}$ pulse may not be optimal for the process efficiency. In this section, we will use the validated model to explore this effect based on above optimization approach. Figure 12 illustrates the optimal cycles for maximum TMA utilization efficiency and alumina production under three different time ratio between TMA half-cycle and $\mathrm{H}_{2} \mathrm{O}$ half-cycle, 60\%:40\%, 50\%:50\% and 40\%:60\%, respectively. The ALD operation temperature is set at $200^{\circ} \mathrm{C}$, while other conditions are the same as above cases and experiment. Obviously, it can be seen that the optimal ALD cycle numbers of three cases are different, where longer TMA half-cycle duration case clearly requires more cycles to achieve optimal process operation. This can be attributed to the relatively slower surface reaction rates of TMA in comparison with $\mathrm{H}_{2} \mathrm{O}$. Besides, it can also be seen that this difference on optimal treatment cycles among three cases are becoming smaller as the total ALD operating time increases. This is because total operating time rise has reduced the influence of limited ALD half-cycle time on the TMA utilization efficiency and alumina production. The effect of different half-cycle durations on the $\mid-\mathrm{Al}\left(\mathrm{CH}_{3}\right)_{2}$ production and alumina film generation is also investigated in figure 13. It shows that the maximum $\mid-\mathrm{Al}\left(\mathrm{CH}_{3}\right)_{2}$ production can be increased to nearly $1 \times 10^{-3} \mathrm{~mol} / \mathrm{m}^{2}$ when the TMA half-cycle duration is increased from $40 \%$ to $60 \%$, while, under the same operating condition, the maximum alumina production is decreased from as high as $0.8 \times 10^{-3} \mathrm{~mol} / \mathrm{m}^{2}$ to around $0.6 \times 10^{-3} \mathrm{~mol} / \mathrm{m}^{2}$. These observations reflect the competing nature of two halfcycle treatments on the surface species production, and indicate that the optimal ALD process requires taking the difference of precursors' reaction rates into consideration, which are determined by the practical ALD operating conditions.

\section{Conclusions}


A combined experimental and modeling study is conducted for ALD of alumina process in this study, using TMA and $\mathrm{H}_{2} \mathrm{O}$ as the metal-source and oxygen-source precursor, respectively. The developed model is based on an ALD of alumina process in Savannah S100 system, and validated by the corresponding experimental results. Based on the developed model, an optimization approach is proposed to investigate the optimal ALD operation for minimizing the TMA waste and maximizing the alumina film production. Results show that due to the different surface reaction rate and conversion efficiency in TMA and $\mathrm{H}_{2} \mathrm{O}$ half-cycles, the maximum TMA adsorption and the maximum alumina production cannot be achieved simultaneously, but supplying sufficient $\mathrm{H}_{2} \mathrm{O}$ dose can minimize the gap between them. Then, three substrate surface saturation conditions, $100 \% \mathrm{C}_{\mathrm{av}}$ (ideal condition), $80 \% \mathrm{C}_{\mathrm{av}}$ and $50 \% \mathrm{C}_{\mathrm{av}}$, are investigated. Results indicate that smaller surface coverage, $50 \% \mathrm{C}_{\mathrm{av}}$ case, requires more $\mathrm{ALD}$ cycles than the other two cases to improve the precursors' utilization efficiency, while the difference of their optimized cycle number increases with the applied total amount of TMA. The effect of ALD operation temperature is also investigated. Numerical results indicate that the optimal ALD process can increase the maximum alumina production from $2.7 \times 10^{-4} \mathrm{~mol} / \mathrm{m}^{2}$ to $7.5 \times 10^{-4} \mathrm{~mol} / \mathrm{m}^{2}$ with the temperature rise from $150^{\circ} \mathrm{C}$ to $200^{\circ} \mathrm{C}$, and the corresponding ALD cycle number increases with the temperature rise. Our experiment on the process $\mathrm{CH}_{4}$ emission and nanoparticle generation also proves that the ALD process designed for maximum TMA utilization efficiency should vary with different operating temperatures. The effect of different half-cycle durations is finally studied. It is found that the maximum production of $\mid-$ $\mathrm{Al}\left(\mathrm{CH}_{3}\right)_{2}$ and alumina is dependent on its corresponding half-cycle operation time, and sufficient ALD operation time can effectively reduce the TMA waste induced from the limited half-cycle time, and increase the alumina deposition efficiency.

\section{Acknowledgement}

The financial support from National Science Foundation (NSF grant number: CMMI-1200940) and UWM Research Growth Initiative (RGI) are gratefully acknowledged. 


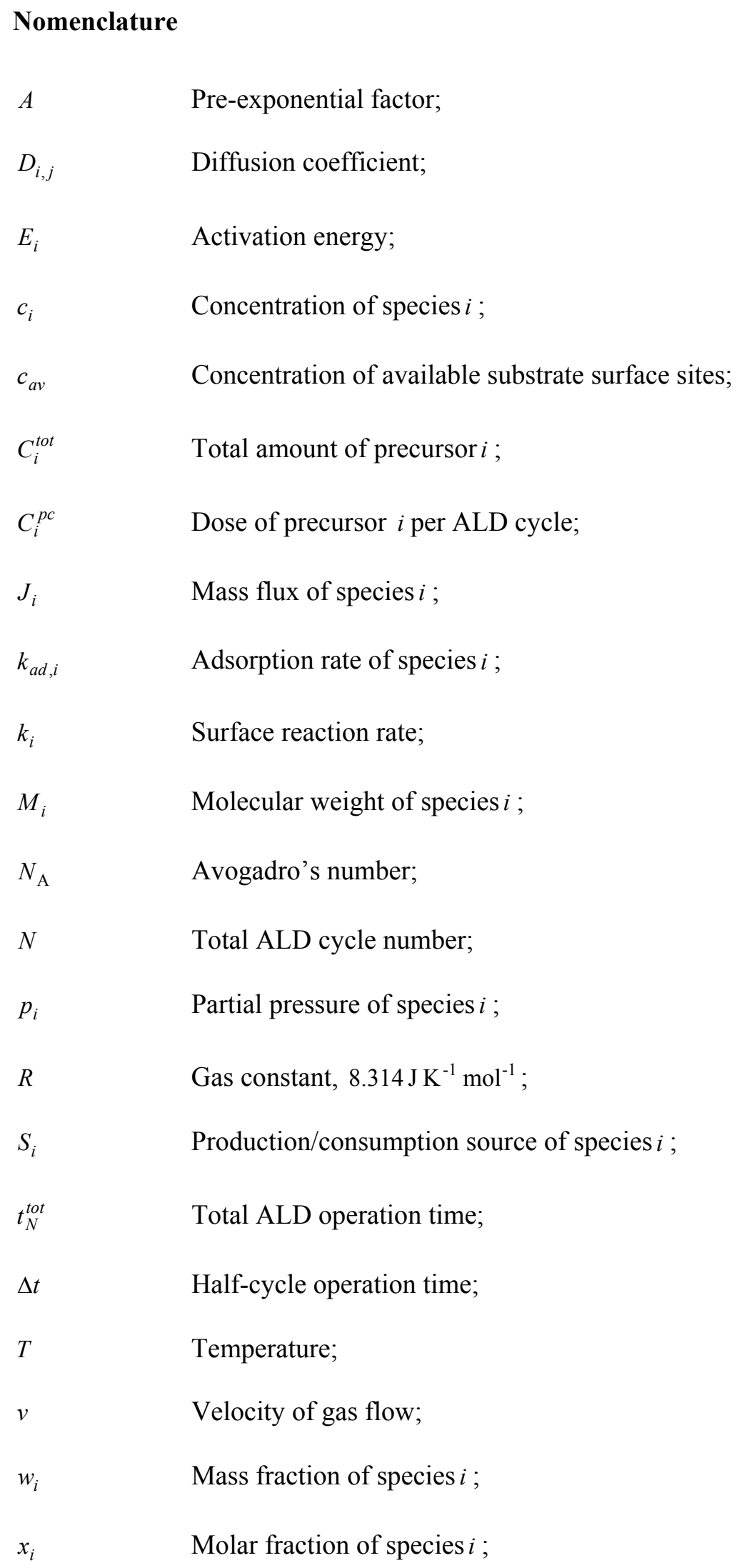


$\rho_{i} \quad$ Density of species $i$

\section{Subscripts}

$\begin{array}{ll}\text { TMA } & \text { Precursor TMA; } \\ \mathrm{H}_{2} \mathrm{O} & \text { Precursor } \mathrm{H}_{2} \mathrm{O} ; \\ p c & \text { Per cycle; } \\ \text { tot } & \text { Total; } \\ \text { pulse } & \text { Precursor pulse; } \\ \text { purge } & \text { Purging period; } \\ \text { rec } & \text { Reactant; } \\ \text { prd } & \text { Product; } \\ \text { gpc } & \text { Growth per cycle }\end{array}$




\section{Reference}

[1] G.Parsons, S.Atanasov, E.Dandley, C.Devine, B.Gong, J.Jur, K.Lee, C.Oldham, Q.Peng, J.Spagnola, P.Williams, "Mechanisms and reactions during atomic layer deposition on polymers", Coordination Chemistry Reviews, 257(2013), 3323-3331;

[2] A. Yanguas Gil, J.Elam, "Simple model for atomic layer deposition precursor reaction and transport in a viscous flow tubular flow", Journal of Vacuum Science \& Technology A, 30(1), 2012, 1-7;

[3] C.Yuan, D. Dornfeld, "Integrated sustainability analysis of atomic layer deposition for microelectronics manufacturing”, Journal of Manufacturing Science and Engineering, 132 (2010), 030918 1-7;

[4] A.Holmqvist, T.Torndahl, S.Stenstrom, "A model based methodology for the analysis and design of atomic layer deposition processes Part I: Mechanistic modelling of continuous flow reactors", Chemical Engineering Science, 81(2012), 260-272;

[5] V.Miikkulainen, M.Leskela, M.Ritala, R.Puurunen, "Crystallinity of inorganic films grown by atomic layer deposition overview and general trends", Journal of Applied Physics, 113(2013), 021301;

[6] R.Puurunen, "A short history of atomic layer deposition: Tuomo suntola's atomic layer epitaxy", Chemical Vapor Deposition, 20(2014), 332-344;

[7] H.Kim, H.Lee, W.Maeng, "Applications of atomic layer deposition to nanofabrication and emerging nanodevices", Thin Solid Films, 517(2009), 2536-2580;

[8] C.Herrmann, F.Fabreguette, D.Finch, R.Geiss, S.George, "Multilayer and functional coatings on carbon nanotubes using atomic layer depsition”, Applied Physics Letter, 87(2005), 123110;

[9] D.Miller, R.Foster, Y.Zhang, S.Jen, J.Bertrand, Z.Lu, D.Seghete, J.Patchen, R.Yang, Y.Lee, S.George, M.Dunn, "The mechanical robustness of atomic layer-and molecular layer-depositied coatings on polymer substrates", Journal of Applied Physics, 105(2009), 093527.1-12; 
[10] J.Lu, B.Liu, N.Guisinger, P.Stair, J.Greeley, J.Elam, "First-principles predictions and in situ experimental validation of alumina atomic layer deposition on metal surfaces", Chemistry of Materials, 26(2014), 6752-6761;

[11] R.Puurunen, J.Saarilahti, H.Kattelus, "Implementing ALD layers in MEMS processing", ECS Transactions, 11(2007), 3-14;

[12] D.Miller, R.Foster, S.Jen, J.Bertrand, S.Cunningham, A.Morris, Y.Lee, S.George, M.Dunn, "Thermo-mechanical properties of alumina films created using the atomic layer deposition technique", Sensors and Actuators A: Physical, 164(2010), 58-67;

[13] N.Hoivik, J.Elam, R.Linderman, V.Bright, S.George, Y.Lee, “Atomic layer deposited protective coatings for micro-electromechanical systems", Sensors and Actuators A: Physical, 1-2(103), 2003, 100108 ;

[14] T.Li, F.Wang, H.Zhang, C.Yuan, "Energy and exergy analyses of atomic layer deposition of Al2O3 nano-film process", International Journal of Energy, 1(2014), 62-75;

[15] C.Yuan, D.Dornfeld, "A schematic method for sustainable material selection of toxic chemicals in design and manufacturing”, ASME Journal of Mechanical Design, 132(2010), 1-7;

[16] R.Puurunen, "Surface chemistry of atomic layer deposition: A case study for the trimethylaluminum/ water process”, Applied Physics Reviews, 97(2005), 121301 1-52;

[17] A.Delabie, S.Sioncke, J.Rip, S.Elshocht, G.Pourtois, M.Mueller, B.Beckhoff, K.Pierloot, "Reaction mechanisms for atomic layer deposition of aluminum oxide on semiconductor substrates", Journal of Vacuum Science \& Technology A, 30(2012), 01A127 1-10;

[18] S.Elliott, J.Greer, "Simulating the atomic layer deposition of alumina from first principles", Journal of Materials Chemistry, 14(2004), 3246-3250; 
[19] M. Shirazi, S.Elliott, "Multiple proton diffusion and film densification in atomic layer deposition modeled by density functional theory", Chemistry of Materials, 25(2013), 878-889;

[20] L.Huang, B.Han, A.Derecskei-Kovacs, M.Xiao, X.Lei, M.ONeil, R.Pearlstein, H.Chandra, H.Cheng, "First princles study of a full cycle of atomic layer deposition of $\mathrm{SiO}_{2}$ thin films with Di silane and ozone", Journal of Physical Chemistry C, 117(2013), 38, 19454-19463;

[21] W.Warburton, W.Henning, J.Bertrand, S.George, S.Biegalski, “Atomic layer deposition alphaA12O3 diffusion barriers to eliminate the memory effect in beta-gamma radioxenon detectors", Journal of Radioanalytical and Nuclear Chemistry, 296(2013), 1, 541-549;

[22] M.Deminsky, A.Knizhnik, I. Belov, S.Umanskii, E.Rvkova, A.Bagaturvants, B.Potapkin, M.Stoker, A.Korkin, "Mechanism and kinetics of thin zirconium and hafnium oxide film growth in a ALD reactor", Surface Science, 549(2004), 67-86;

[23] C.Travis, R.Adomaitis, "Modeling ALD surface reaction and process dynamics using absolute reaction rate theory", Chemical Vapor Deposition, 19(2013), 4-14;

[24] C.Travis, R.Adomaitis, "Modeling alumina atomic layer deposition reaction kinetics during the trimethylaluminum exposure", Theoretical Chemistry Accounts, 133(2014), 1414-1425;

[25] A.Holmqvist, T.Torndahl, S.Stenstrom, "A model based methodology for the analysis and design of atomic layer deposition processes Part II: Experimental validation and mechanistic analysis", Chemical Engineering Science, 94(2013), 316-329;

[26] A.Holmqvist, T.Torndahl, S.Stenstrom, "A model based methodology for the analysis and design of atomic layer deposition processes Part III: Constrained multi-objective optimization", Chemical Engineering Science, 96(2013), 71-86; 
[27] A.Holmqvist, T.Torndahl, F.Magnusson, U.Zimmermann, S.Stenstrom, "Dynamic parameter estimation of atomic layer deposition kinetics applied to in situ quartz crystal microbalance diagnostics", Chemical Engineering Science, 111(2014), 15-33;

[28] Y. Xie, L.Ma, D.Pan, C.Yuan, "Mechanistic modeling of atomic layer deposition of alumina process with detailed surface chemical kinetics", Chemical Engineering Journal, 259(2015), 213-220;

[29] L.Ma, D.Pan, Y.Xie, C.Yuan, "Atomic layer deposition of Al2O3 process emissions", RCS Advances, 5(2015), 12824-12829;

[30] D.Pan, L.Ma, Y.Xie, C.Yuan, "On the physical and chemical details of alumina atomic layer deposition: A combined experimental and numerical approach", Journal of Vacuum Science \& Technology A, 33(2015), 021511;

[31] O.Ylivaara, X.Liu, L.Kilpi, J.Lyytinen, D.Schneider, M.laitinen, J.Julin, S.Ali, S.Sintonen, M.Berdova, E.Haimi, T.Sajavaara, H.Ronkainen, H.Lipsanen, J.Koskinen, S.Hannula, R.Puurunen, "Aluminum oxide from trimethylaluminum and water by atomic layer deposition: the temperature dependence of residual stress, elastic modulus, hardness and adhesion”, Thin Solid Films, 552(2014), 124-135;

[32] M.Ghosh, C.Choi, "The initial mechanisms of Al2O3 atomic layer deposition on $\mathrm{OH} / \mathrm{Si}(100)$ surface by tri-methylaluminum and water", Chemical Physics Letters, 426(2006), 365-369;

[33] E.L.Cussler, Diffusion-Mass Transfer in Fluid Systems (3rd Edition), 2007, Cambridge. 
Table 1 ALD mathematical model

\begin{tabular}{|c|c|c|}
\hline $\begin{array}{l}\text { Chemical } \\
\text { kinetics: }\end{array}$ & 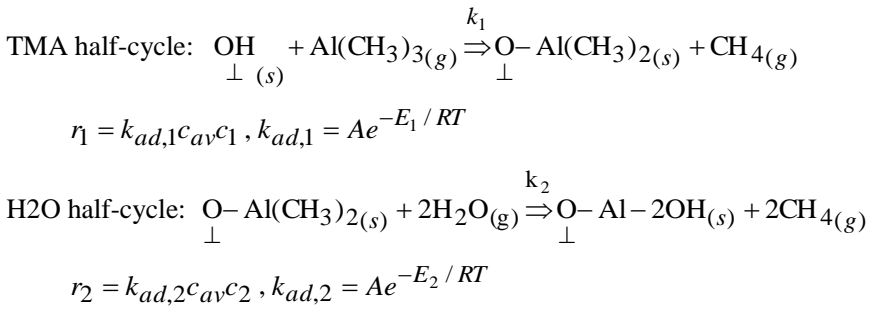 & (r1) \\
\hline Momentum: & 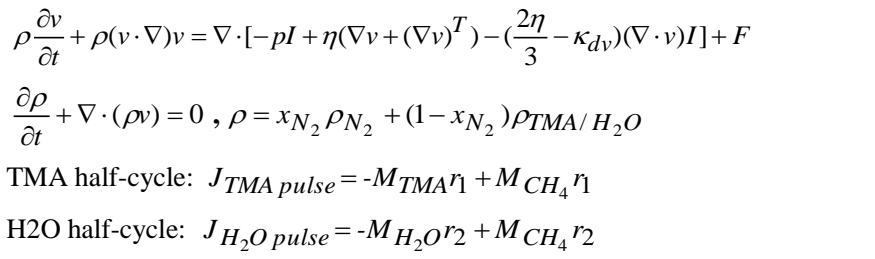 & $\begin{array}{l}\text { (1) } \\
(2) \\
\text { (3) }\end{array}$ \\
\hline Mass: & $\begin{array}{l}\frac{\partial \rho w_{i}}{\partial t}+\nabla \cdot\left(\rho w_{i} v\right)+\nabla \cdot J_{i}=S_{i} \\
J_{i}=-\rho w_{i} \sum_{j} D_{1 j}\left[\nabla x_{j}+\left(x_{j}-w_{j}\right) \nabla p / p\right] \\
\text { TMA half-cycle: } J_{T M A}=-M_{T M A} r_{1}, J_{C H_{4}}=M_{C H_{4}} r_{2} \\
\text { H2O half-cycle: } J_{H_{2} O}=-M_{H_{2} O} r_{1}, J_{C H_{4}}=M_{C H_{4}} r_{2}\end{array}$ & $\begin{array}{l}\text { (4) } \\
(5) \\
\text { (6) }\end{array}$ \\
\hline
\end{tabular}

Table 2 Operating parameters ${ }^{[23,33]}$

\begin{tabular}{|c|c|c|c|}
\hline & Value & & Value \\
\hline Gas phase density of TMA: & $3.281 \mathrm{~kg} \mathrm{~m}^{-3}$ & Maximum |-OH surface density: & $17.2 \mathrm{~nm}^{-2}$ \\
\hline Water vapor density: & $2.897 \mathrm{~kg} \mathrm{~m}^{-3}$ & $\begin{array}{l}\text { Maximum } \mathrm{Al}_{1} \mathrm{O}_{3 / 2} \text { surface } \\
\text { density: }\end{array}$ & $11.5 \mathrm{~nm}^{-2}$ \\
\hline $\mathrm{N}_{2}$ gas density: & $1.251 \mathrm{~kg} \mathrm{~m}^{-3}$ & TMA adsorption energy: & $-0.61 e V$ \\
\hline $\mathrm{CH}_{4}$ gas density: & $0.656 \mathrm{~kg} \mathrm{~m}^{-3}$ & Water adsorption energy: & $-0.57 e V$ \\
\hline Gas constant: & $8.314 \mathrm{~J} \mathrm{~mol}^{-1} \mathrm{~K}^{-1}$ & Total TMA amount: & $0.1 \mathrm{M}$ \\
\hline Inlet pressure $\left(\mathrm{N}_{2}\right), p_{\text {inlet }}$ : & 1 Torr & Operation temperature: & $200^{\circ} \mathrm{C}$ \\
\hline outlet pressure $\left(\mathrm{N}_{2}\right), p_{\text {outlet }}$ : & 0.9 Torr & Diffusion coefficient, $D_{N_{2}, T M A}$ : & $2.656 \times 10^{-4} \mathrm{~m}^{2} \mathrm{~s}^{-1}$ \\
\hline Total ALD operation time: & $200 s$ & Diffusion coefficient, $D_{\mathrm{N}_{2}, \mathrm{H}_{2} \mathrm{O}}$ : & $2.2817 \times 10^{-4} \mathrm{~m}^{2} \mathrm{~s}^{-1}$ \\
\hline TMA pulse duration: & $0.015 s$ & Diffusion coefficient, $\mathrm{D}_{\mathrm{N}_{2}, \mathrm{CH}_{4}}$ : & $1.9043 \times 10^{-4} \mathrm{~m}^{2} \mathrm{~s}^{-1}$ \\
\hline $\mathrm{H}_{2} \mathrm{O}$ pulse duration: & $0.03 s$ & Diffusion coefficient, $D_{T M A, C H_{4}}$ : & $3.748 \times 10^{-4} \mathrm{~m}^{2} \mathrm{~s}^{-1}$ \\
\hline Purging process duration: & $8 s \sim 10 s$ & Diffusion coefficient, $\mathrm{D}_{\mathrm{H}_{2} \mathrm{O}, \mathrm{CH}_{4}}$ : & $2.3185 \times 10^{-4} \mathrm{~m}^{2} \mathrm{~s}^{-1}$ \\
\hline
\end{tabular}



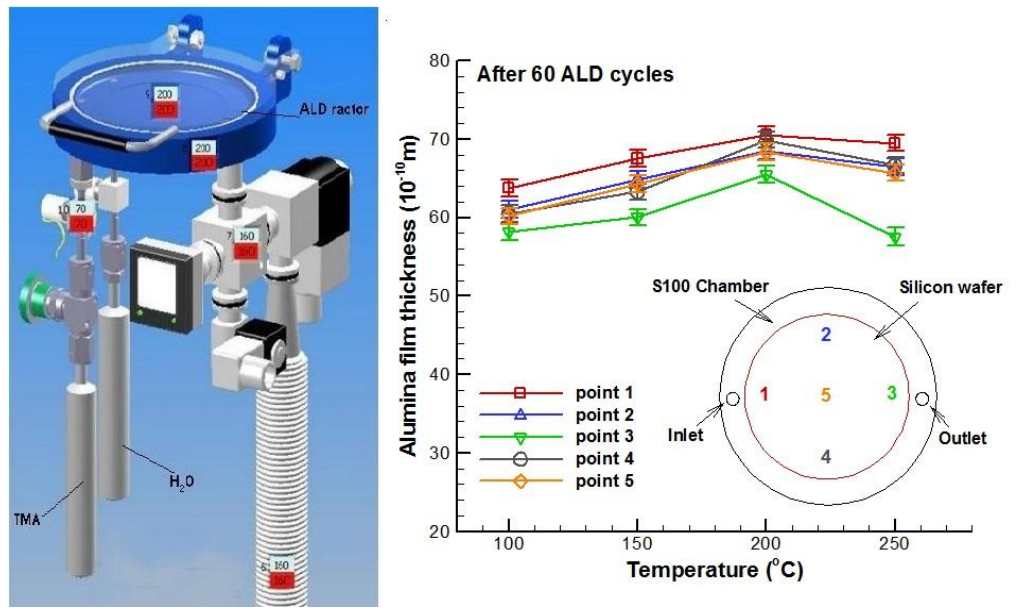

Fig.1 Schematic of ALD experimental system and the obtained alumina film thickness on silicon wafer surface after 60 cycles. The symbols present thickness values and bars denote the error values.
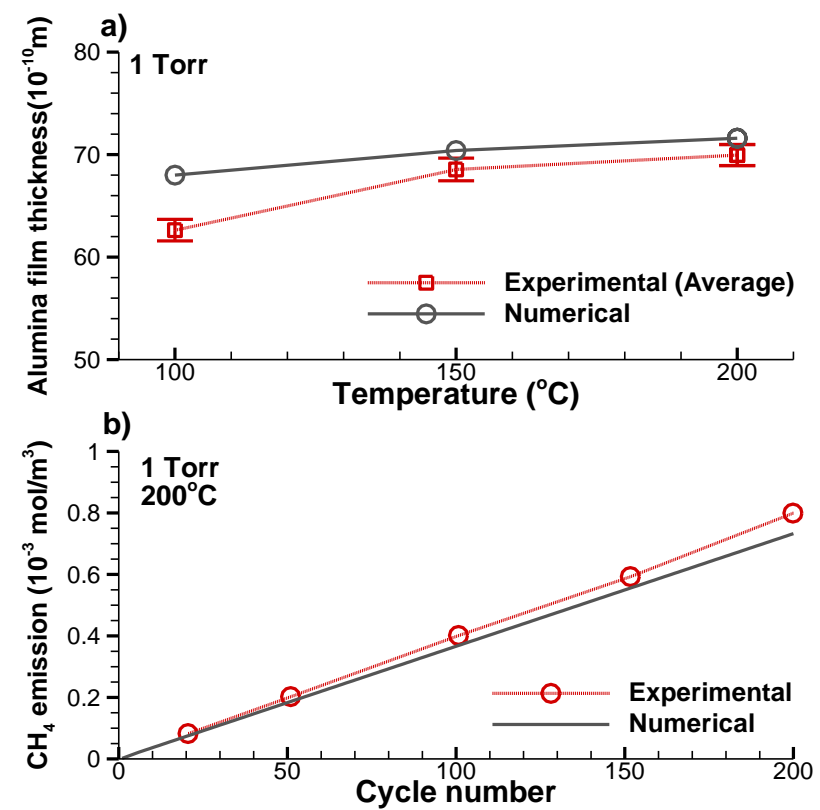

Fig.2 Comparison between the numerical results and experimental data: a) deposited alumina film thickness, where symbols present the thickness values and bars stand for the error values; b) $\mathrm{CH}_{4}$ in process emissions. 


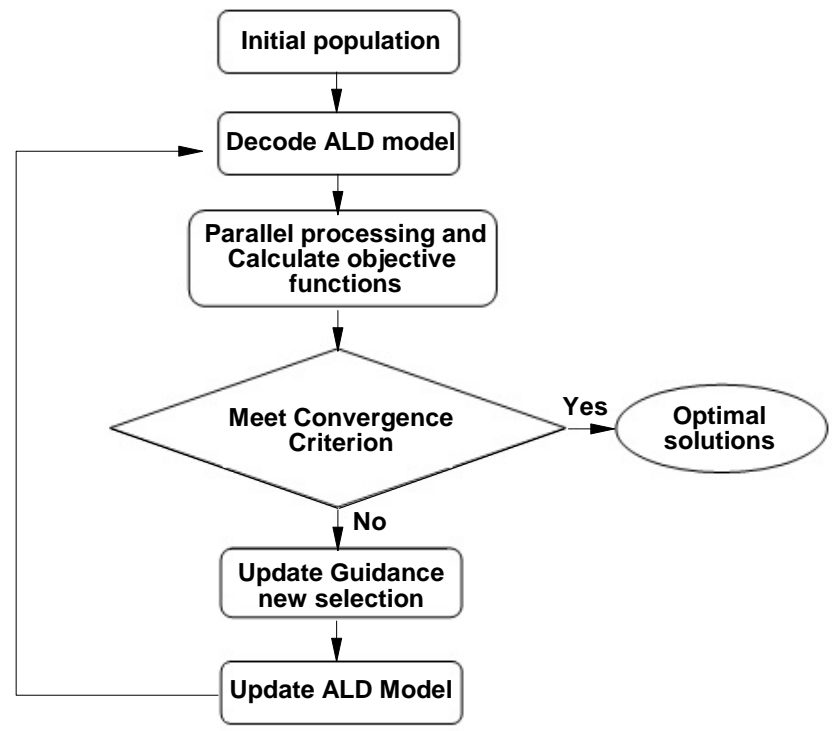

Fig.3 Flowchart of ALD model based optimization procedure

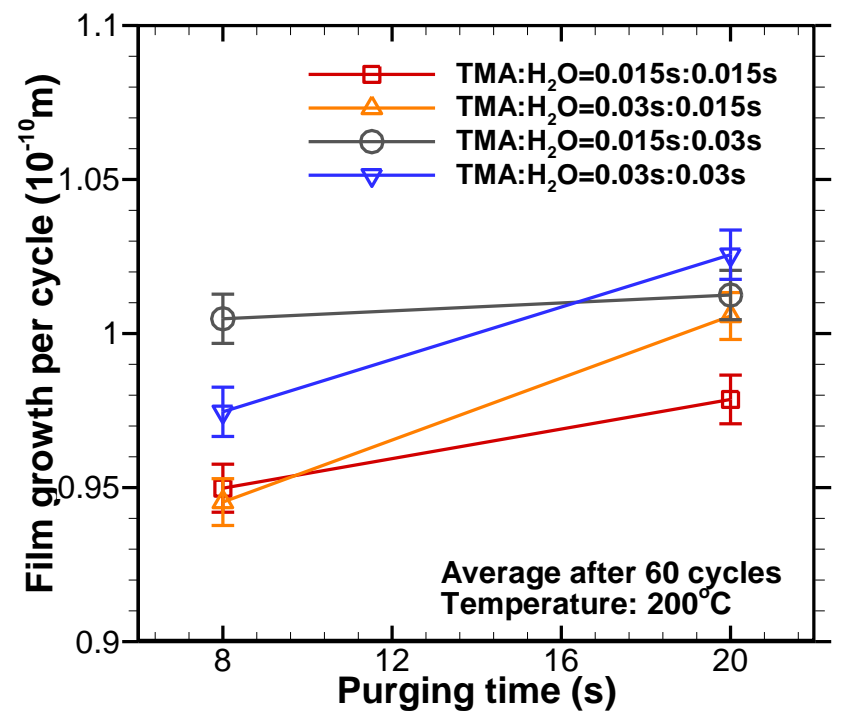

Fig.4 Alumina film growth per cycle (GPC) under different precursor dose conditions, which are controlled by the duration of two precursor pulses $(0.015 \mathrm{~s}$ or $0.03 \mathrm{~s})$. The symbols present thickness values and bars stand for the error values. 


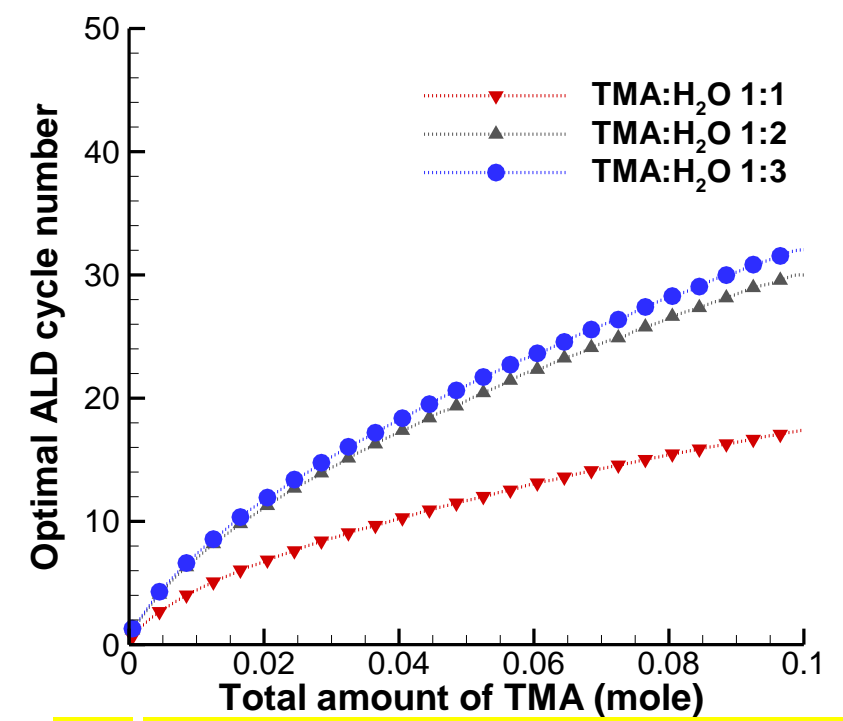

Fig.5 The optimized ALD operation under different given total TMA, where three $\mathrm{H}_{2} \mathrm{O}$ dose conditions (different molar ratio, $1: 1 ; 1: 2 ; 1: 3$ ) are simulated and compared.
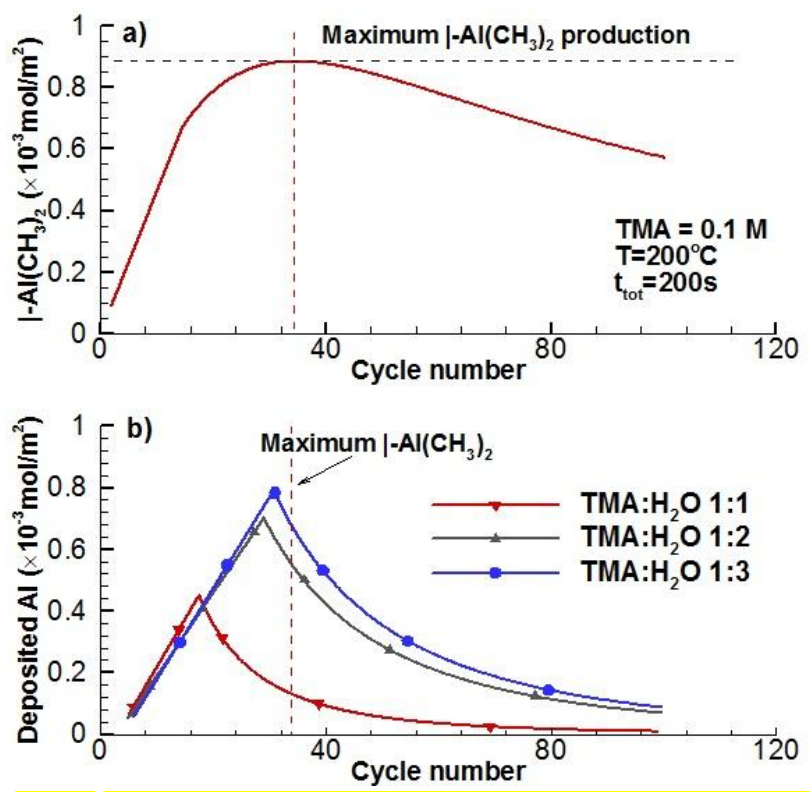

Fig.6 Effect of designed ALD cycles on the a) surface species $\mid-\mathrm{Al}\left(\mathrm{CH}_{3}\right)_{2}$ production and $\mathrm{b}$ ) alumina deposition. The influences by different $\mathrm{H}_{2} \mathrm{O}$ dose (different molar ratio, $1: 1 ; 1: 2 ; 1: 3)$ are compared. 


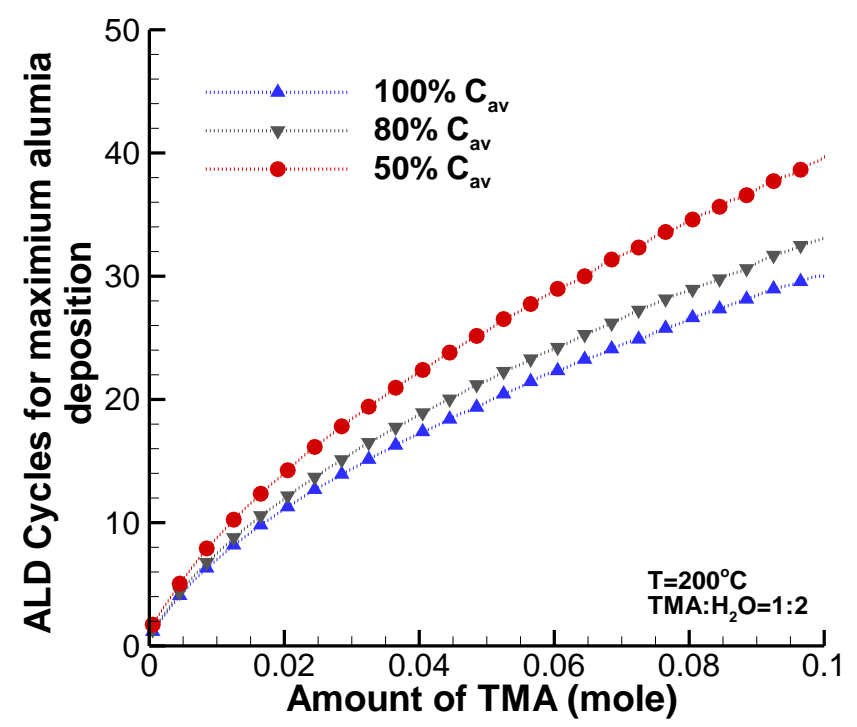

Fig.7 The optimized ALD operation under different given treatment time, where three substrate surface conditions are compared.
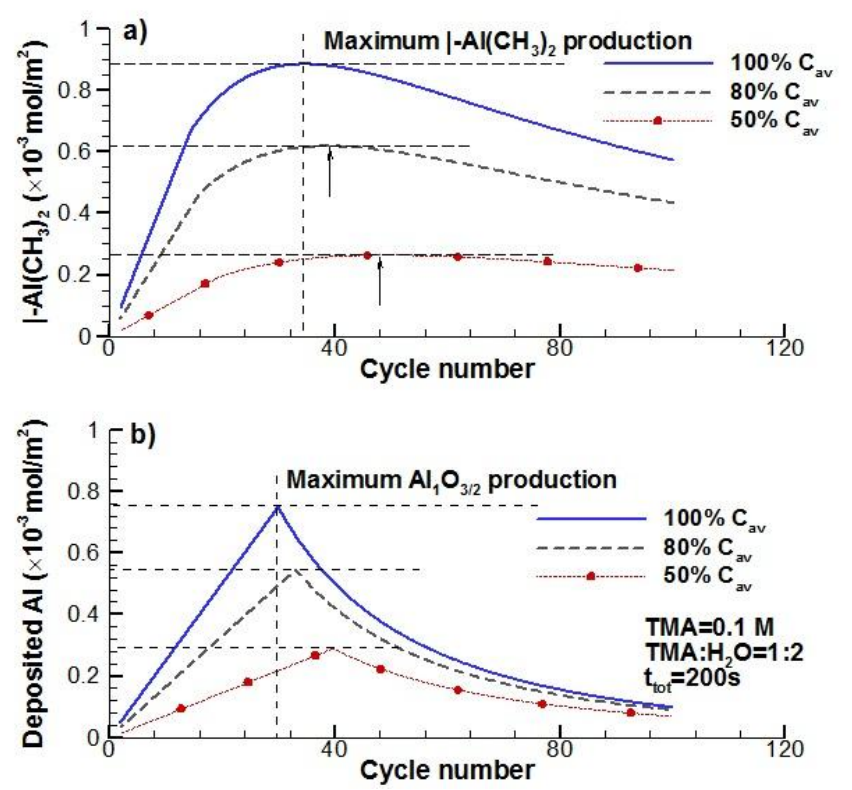

Fig.8 Effect of substrate surface condition on the a) surface species $\mid-\mathrm{Al}\left(\mathrm{CH}_{3}\right)_{2}$ production and $\left.\mathrm{b}\right)$ alumina deposition under different designed ALD cycles 


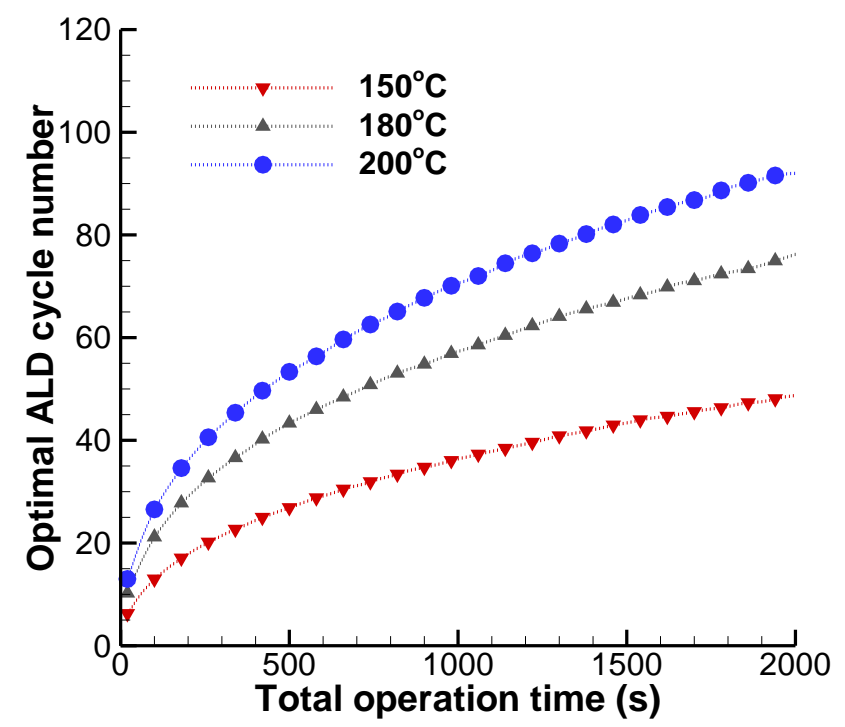

Fig.9 The optimized ALD operation under different given treatment time, where three operation temperature conditions are compared.
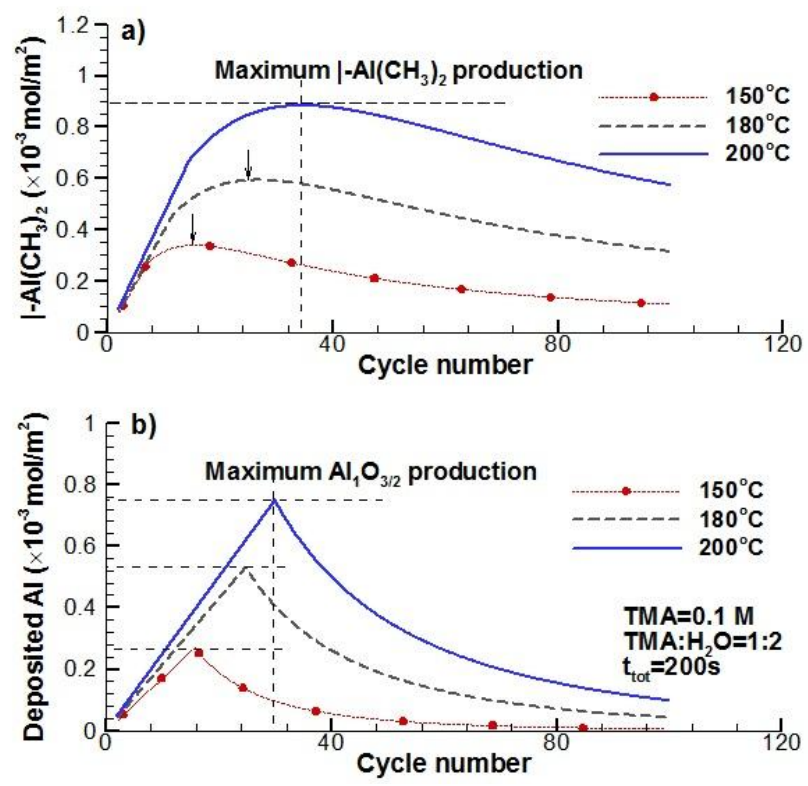

Fig.10 Effect of operation temperature on the a) surface species $\mid-\mathrm{Al}\left(\mathrm{CH}_{3}\right)_{2}$ production and $\left.\mathrm{b}\right)$ alumina deposition under different designed ALD cycles 

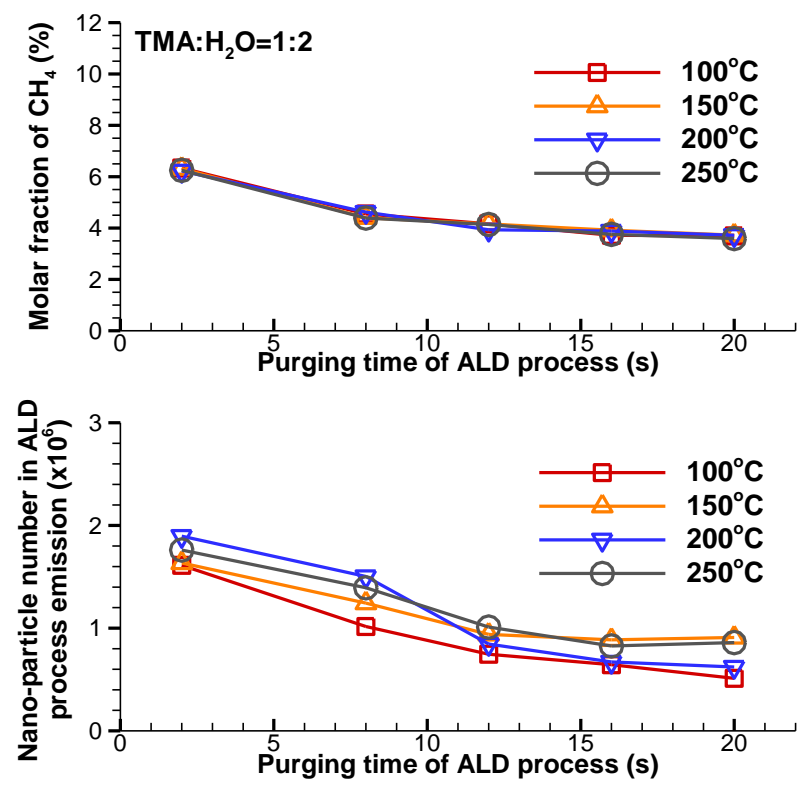

Fig.11 Effect of operation temperature and ALD purging time on the production of a) $\mathrm{CH}_{4}$ and b) nanoparticles in the process emission

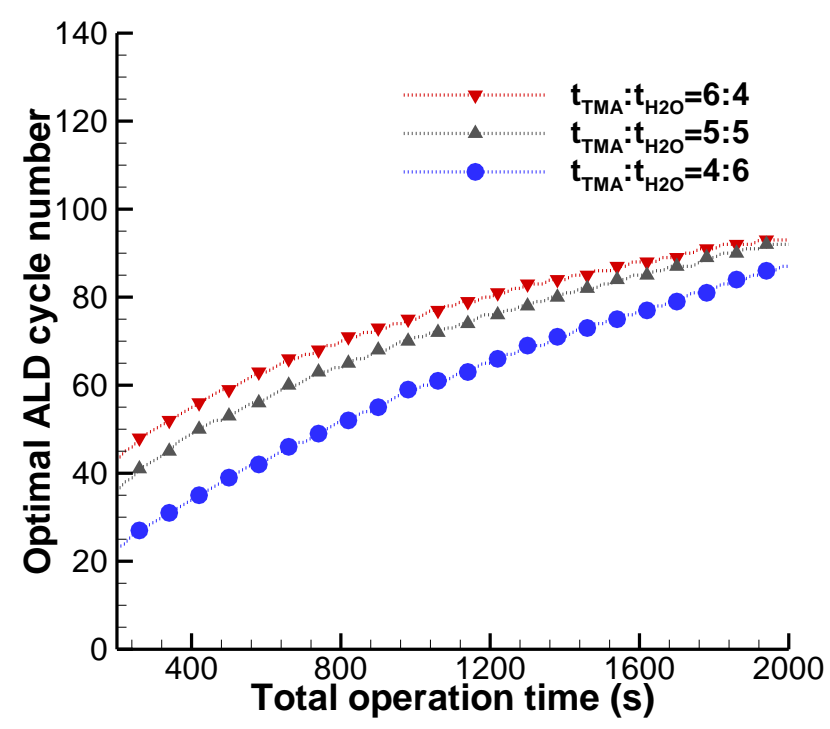

Fig.12 The optimized ALD operation under different total treatment time, where three half-cycle duration ratios are simulated and compared. 

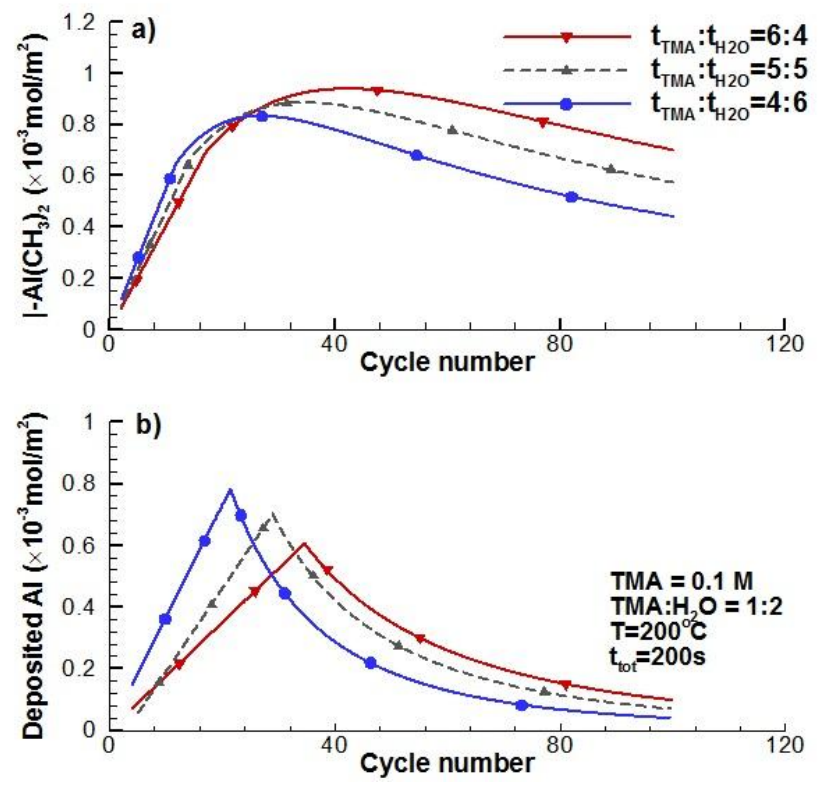

Fig.13 Effect of ALD half-cycle durations on the a) surface species $-\mathrm{Al}\left(\mathrm{CH}_{3}\right)_{2}$ production and $\mathrm{b}$ ) alumina deposition under different designed ALD cycles. 